\title{
GESTIÓN DE CENTROS: ALGUNAS REFLEXIONES Y APORTES
}

\author{
"La realidad está ahí y nosotros en ella, \\ entendiéndola a nuestra manera pero en ella" \\ J. Cortázar
}

Mag. Ruth E. Cruz Cárdenas*

\section{Introducción}

Cuando nos referimos a centros educativos, lo hacemos, a veces, destacando algunas de sus características; así, podemos decir que uno atiende especialmente la formación de la persona; este otro otorga status al que asiste a él; aquel es muy exigente a la hora de evaluar a sus alumnos y así podríamos continuar dando ejemplos de cómo se identifica una institución educativa en la comunidad.

Al entrar por primera vez a un centro se reciben "mensajes" sutiles, a través de la percepción de actitudes, de ambientes percibidos, de expresiones, de presencias o de ausencias, que permiten captar un clima, una cultura, pautas, valores, prioridades institucionales. Esto tiene mucho que ver con el proyecto educativo, con el curriculum institucional, explicitado o no, pero también con el estilo de gestión. La gestión está hoy en la agenda de los Directivos de instituciones educativas, en el discurso de muchos, en la currícula de las instituciones de formación de recursos; en una palabra, está en la mira. La gestión se ha constituido en un tema central, sustantivo a la hora de pensar en el cambio orientado a mejorar los niveles de calidad. Esto ocurre en nuestro ámbito, con más énfasis en los últimos años.

Innovar la gestión de los centros educativos, mejorarla, enmarcarla en ciertos principios teóricos, es considerado actualmente como una estrategia fundamental para la generación de cambios cualitativos. Nos preguntamos, ¿en el pasado no hubo gestión de los centros educativos? Sí, claro que sí. Lo que ocurre es que se ha modificado el paradigma: la teoría que da marco al análisis institucional y a la actuación de los Directores de centros, como promotores de cultura institucional.

Quizás en el pasado, a la hora de pensar en la obtención de un mayor nivel de logro, se puso especial expectativa en la importancia de los recursos materiales, en la inversión, en el cambio de los programas, en fin, en componentes específicos de la dimensión pedagógico - didáctica de la institución educativa, desconociendo la incidencia que sobre esta dimensión tienen las decisiones tomadas en aspectos organizacionales y administrativos. Es esencial hacer visible los valores, los supuestos, los principios, las prioridades sobre los cuales se decide y por los que se genera política institucional y se impacta en aspectos institucionales sustantivos. Hoy sabemos que la organización también enseña y, en este sentido, es fundamental "hacer visible lo invisible"

Para modernizar el modelo de gestión institucional es necesario integrar algunos cambios en la concepción de la institución, en su naturaleza y composición, en el rol del Director, fundamentalmente en relación con la forma de vincularse con los distintos sectores de la comunidad educativa. Sin duda aquí sí que es cierto aquello de que "del dicho al hecho hay un gran trecho", porque es difícil romper en nuestras estructuras mentales esquemas de comportamiento, modificar nuestras concepciones y valores en los cuales se sustentaron por años las decisiones y acciones cotidianas; y esto no sólo no es sencillo para quienes tienen la tarea de gestionar el centro, sino que lo es también para los demás actores de la institución; exige cambios en los directivos pero también en el imaginario colectivo de los demás actores. 


\section{¿Qué es la gestión?}

El diccionario relaciona la gestión con el "dar pasos conducentes a la consecución de una cosa". Pozner (1997: 70) la define como un "conjunto de acciones articuladas entre sí, que emprende el equipo directivo en la institución, para promover y posibilitar la consecución de la intencionalidad pedagógica en y con la comunidad educativa" Por su parte Aguerrondo (1992) relaciona la gestión con el campo de la "gerencia", es decir, se trata de poner en práctica y cuidar, especialmente, el cumplimiento de los mecanismos necesarios para alcanzar el logro de los objetivos institucionales.

En la esencia del concepto podemos reconocer: por un lado, la importancia de la acción, por otro, su orientación al logro de ciertos objetivos, de distinta naturaleza según la especificidad de la institución. Para el logro de esos objetivos se toman decisiones, en el caso de la institución escolar, sobre recursos de distinta naturaleza, mediante saberes que tienen que ver con teorías de la organización y de lo pedagógico-didáctico, organizando y administrando actividades y recursos, desarrollando un curriculum que hace a lo específico institucional. Aunque no seamos conscientes de las teorías que subyacen, que orientan y dan marco a las decisiones, las mismas están y es importante que las conozcamos, que las explicitemos para tratar de ser convergentes, para generar efectos sinérgicos y no divergentes en nuestra acción. Se trata de tener elementos, apoyos teóricos para hacer una "lectura" de la realidad, para analizarla críticamente y reorientarla si fuera necesario.

Es oportuno aquí hacer referencia a Poggi (1998:35) quien nos dice que la gestión educativa "implica construir saberes teóricos y prácticos en relación con la organización del establecimiento escolar, con las cuestiones de la administración, con la vinculación con los organismos centrales del gobierno escolar, con los actores que forman parte de la institución, con otras instituciones, etc."

En general, quienes dirigen las instituciones educativas, lo hacen fundamentalmente, mediante saberes construidos en la misma práctica, tomados de su historia personal y profesional, conocimientos generados sobre la base de ciertos supuestos básicos, tradicionales. El modelo de carrera docente, que va del maestro o profesor de aula a Director, está indicando que tradicionalmente se ha creído que de un buen docente de aula podría esperarse un buen desempeño como directivo, sobre la base de una concepción restringida de gestión, sustentada en los saberes pedagógicos, y no en los de naturaleza política, administrativa y organizacional. Cuando pensamos en un estilo actual de gestión, la concertada, la asociamos a la participación, a la cooperación, a la descentralización, a la elaboración de proyectos de centro, a la evaluación cualitativa, a la planificación estratégica, entre otros conceptos.

Es necesario que nos detengamos en algunos aspectos esenciales que dan marco a este estilo de gestión y que conducen a la construcción de un saber reflexivo acerca del centro.

\section{Algunos conceptos claves}

\section{La institución}

La institución es una forma esencial de regulación social; la sociedad crea instituciones y les delega a ellas parcelas, sectores de la acción social. A la institución escolar le entrega la producción y la distribución de los conocimientos socialmente válidos, la consolidación del entramado social y cultural, le demanda la formación de los ciudadanos, de los recursos para el mundo del trabajo y de la ciencia. Esta institución, como todas, funciona mediante una organización, que es el aspecto más concreto y visible de ella. Es la organización la que permite alcanzar los objetivos que hacen a la esencia de la institución. Las organizaciones sociales, a diferencia de las de naturaleza biológica o mecánica, son menos previsibles, se alejan más de modelos preestablecidos, porque están integradas por personas, son

8 - Universidad ORT Uruguay 
de naturaleza humana.

Existen teóricos que tradicionalmente han concebido a la institución, y abordan su análisis organizacional, en el marco de una racionalidad absoluta. Son aquellos que conciben a la institución y a su organización desde una lógica por la cual todo alejamiento de la normalidad prefijada, del comportamiento esperado, normatizado, debe ser reconducido hacia el funcionamiento deseado. Así es que, con las diferencias de cada caso, tenemos teorías de gran desarrollo en nuestro siglo, como las de Max Weber, Taylor y Elton Mayo, algunas de las cuales ha tenido un papel casi hegemónico en cuanto a analizar, comprender y hacer funcionar eficazmente a las instituciones.

En las tres últimas décadas, fundamentalmente a partir de los aportes de Crozier, la forma de abordar la problemática humana en la organización ha sido criticada y reconsiderada. En el marco de una teoría de racionalidad relativa, se concibe a la institución social como un ente dinámico, no acabado mediante una definición de normas que pautan su esencia, su organización y funcionamiento. La institución se concibe como un "constructo"; es algo que se construye permanentemente mediante la interacción de sus actores, no preexiste de modo absoluto al individuo que la integra, sino que es un producto, en el cual el sistema y el actor se relacionan dialécticamente. Como expresa Frigerio (1997), no somos parte o engranajes de una máquina, sino "arquitectos y habitantes" de las instituciones, construimos la cotidianeidad mediante nuestras interacciones con otros y con las normas.

La institución educativa tiene, al igual que otras, una naturaleza multidimensional. Reconocemos, en primer lugar, la que hace a su especificidad, a su esencia - la dimensión pedagógico - didáctica, al servicio de la cual están la administrativa, la organizacional y la comunitaria. No descuidar esa esencialidad institucional es clave para la gestión.

\section{El Director y el docente de aula}

Este nuevo estilo de gestión se da sobre un sustento teórico consistente, integrado por algunas ideas básicas. Es preciso referirnos al docente, a quien se le concibe como un agente reflexivo, activo, creador, hacedor de su práctica. Concibe a la profesión docente como una práctica "hermenéuticoreflexiva", al decir de Gimeno Sacristán y Pérez Gómez (1995, pág.95). No sería válida en este modelo de gestión una concepción "tecnicista" del docente, que sólo ejecuta lo que otros diseñan, ni tampoco aquella de índole "artesanal" por la cual el docente implementa lo que otros van transmitiendo como válido, de generación en generación. Este estilo de gestión requiere de un docente comprometido con su práctica, generador de teoría, que integra y promueve una cultura de participación, de trabajo en equipo.

El Director de la institución es un actor clave en la gestión y aquí va otra idea esencial. El Director es importante y aunque no todos los logros dependen de él, sí puede echar todo a perder. La toma de decisiones y la delegación de tareas son aspectos esenciales en su gestión, como también lo es su liderazgo para generar las condiciones necesarias para una gestión concertada.

\section{El poder y los conflictos en la institución.}

La institución está compuesta por personas, por actores, que se desempeñan en sus funciones, establecen relaciones, intercambian información, hacen uso de su cuota de poder. Este poder está presente en cada actor, sea reconocido o no por las jerarquías institucionales. Tradicionalmente se ha creído que quienes cuentan con poder son solamente los directivos, las autoridades en la escala jerárquica, los de más arriba en el organigrama institucional. Es aquí donde aparece una novedad esencial para el cambio de gestión: reconocer que todos tienen poder y lo ejercen conscientemente o no.

Las normas dentro de una institución son esenciales, hacen a la puesta en marcha de su funcionamiento, de su engranaje organizacional. Las mismas ponen límites, coartan la libertad de actuar 
y por eso son vistas como un perjuicio; sin embargo son ellas las que nos dan certidumbre, seguridad dentro de la institución. Si no existieran, las reclamaríamos. Pero a diferencia de las concepciones tradicionales de racionalidad absoluta, esta normativa no prevé todas las situaciones de una institución y su compleja dinámica: no es posible normatizar todo. Así, quedan ciertas franjas de incertidumbre, márgenes de libertad que cada actor utiliza de distinta manera y es ahí donde se manifiesta su poder.

Este poder se hace visible cuando aparecen situaciones conflictivas, en las que se enfrentan intereses, visiones, actitudes y es en esta circunstancia en que se hace necesaria la negociación. En lugar de imponerse con otra norma o de desconocer la problemática o de enfrentarla con rigor, es preciso generar un proceso de negociación. La negociación comienza por reconocer al otro y su cuota de poder, para luego generar un espacio para el intercambio, en el cual cada uno cede y renuncia a algo.

Generalmente los conflictos se perciben como algo negativo, evitable, cuando en realidad los conflictos son inherentes a la dinámica institucional; son consecuencia de un funcionamiento natural de la institución como "constructo". He aquí una diferencia fundamental entre la gestión tradicional y la que actualmente se promueve. Los conflictos habitualmente se combaten, se ven como una "patología" de la institución que es necesario eliminar mediante la autoridad o la norma; en otras ocasiones se ignoran, se ocultan, se les deja en estado latente, en el marco de una gestión sustentada en una lógica de racionalidad absoluta. Al producirse los conflictos, se observa el marco en el cual se procede a abordarlos, si desde un estilo jerárquico, en el que se considera que el poder y el saber se concentra sólo en la Dirección o si de verdad se cree que todos los actores tienen un potencial cognitivo, un bagaje de experiencia para compartir y considerar.

Debemos empezar por reconocer las diferencias individuales como personas y como profesionales. Tenemos historias de vida personal y profesional que nos hacen diferentes, y por lo tanto, la manifestación de esas diferencias es crucial para la forma en que enfrentamos ese conflicto, en una organización abierta, participativa. Es a partir de las diferencias que juntos construimos un camino común que nos une hacia las metas del proyecto educativo institucional. Los sentimientos, las emociones se concentran en la pasión de la acción profesional, no con relación a personas, a individualidades; el círculo de leales y de enemigos a la Dirección no tiene lugar en este estilo concertado de gestión. Estos vínculos afectivos que impregnan la tarea, unidos a la preeminencia de canales informales por los cuales fluye la información, por inexistencia o insuficiencia de los formales, caracterizan, entre otros, a una institución de gestión familiar.

Existen sin duda afinidades y oposiciones, desencuentros profesionales, que se constituirán en generadores de acción y de enriquecimiento recíproco. No se trata de ganar o perder frente al conflicto, no son personas las que se oponen, son puntos de vista, perspectivas, y es preciso que la Dirección, fundamentalmente, tenga la humildad de reconocer errores y aceptar posturas más relevantes que las propias. No olvidemos: la negociación es muy importante en una cultura institucional concertada y en toda gestión profesional.

\section{La participación, los equipos de trabajo}

En estos últimos años, se ha dado la aparición de nuevos modelos organizacionales que transforman el sentido común en tendencias, entre otras, que van de las pirámides jerárquicas cerradas a redes interactivas abiertas, de la planificación y estandarización a la flexibilidad y adaptabilidad. Esta lógica conduce a la existencia de organizaciones en red, en la que se produce una descentralización en la toma de decisiones, se fortalece el trabajo cooperativo, en equipo, se da un mayor contacto con los agentes externos, con la comunidad.

El trabajo en equipo es un aspecto esencial a este nuevo estilo de gestión. La tarea docente suele ser muy individualista, muy encerrada en el aula, es por eso que la construcción de esa cultura del encuentro, del compartir, de la "suma positiva" no es fácil de alcanzar. Requiere de un esfuerzo permanente 
y los escollos no deben desalentar a quienes emprenden el camino de una gestión participativa. Senge (1992) expresa que quien ha conocido el placer, la satisfacción del trabajo en equipo y sus logros, no lo olvida y lo busca siempre. Se aprende de esta experiencia y las instituciones que basan su funcionamiento en la cooperación pasan a ser organizaciones inteligentes. Siempre se ha creído que los únicos que pueden aprender, y que aprenden, en una escuela son los alumnos; actualmente se entiende a la institución como un centro de formación permanente para el docente, no solamente a través de acciones curriculares específicas, sino mediante una forma de ejercicio de la profesión. Quizás sea impensable para un docente hoy realizar la observación de la práctica de aula de un colega para luego hacer la crítica constructiva de la misma y el intercambio profesional, en el marco de una investigación - acción.

\section{Hacia la construcción del saber reflexivo Un analizador institucional: la agenda del Director}

A veces observamos que la gestión de una institución se desarrolla a través de prácticas sustentadas en bases poco científicas; muchas veces escuchamos fundamentar la acción en expresiones como estas: "siempre se hizo así", "me lo dijeron en un curso", "lo leí y me gustó", "así me lo enseñaron y así lo hice siempre", "hace años que lo hago y siempre me dio resultado", "se está haciendo así en tal Colegio", "está de moda". Frecuentes prácticas se cumplen por inercia, apoyadas en saberes intuitivos, sin reflexión o en saberes parciales acumulados.

Pertenecemos a instituciones desde que nacemos; nos desarrollamos y socializamos en ellas; son ámbitos de trabajo y de profesionalización y sin embargo, en general nos vemos superados por ellas. Así es que entre los gestionarios de una institución encontramos una amplia tipología integrada por "adictos al trabajo", "burros de carga", "expertos en eficiencia", "indecisos", "gerentes de la crisis", "sociables". Esta clasificación que pertenece a Batley y nos la aporta Frigerio y otras ( 1992:21), tal vez nos permita reconocernos. Como decíamos anteriormente, podemos estar de acuerdo en muchas ideas que se han expresado, lo difícil es llevarlas a la práctica, internalizarlas, implementarlas. Construir la viabilidad de este estilo de gestión, pasar del saber intuitivo al reflexivo no es fácil, sobre todo, en actores que se enfrentan a diario con una dinámica institucional muy fuerte, en la que los emergentes, los imprevistos se imponen a lo planificado.

Nos parece oportuno sugerir el uso de instrumentos que permitan el análisis de la gestión: uno de ellos es la agenda del Director. Es un organizador de lo cotidiano, un "analizador" institucional y tiene el valor de permitirnos vernos como gestionarios.

Se trata de registrar diariamente las actividades cumplidas, luego clasificarlas según distintos criterios: por su naturaleza, por su pertenencia a cada una de las dimensiones, por el tiempo dedicado, por su carácter previsible o no, por ser de atención urgente o por su nivel de relevancia. También nos permite reconocer la transferibilidad de las tareas que nos ocupan y por lo tanto evaluar cómo está funcionando la delegación de tareas.

A propósito de la agenda del Director, comparto con ustedes el resultado de una investigación realizada en la Universidad de Harvard, por la cual se analizaron las actividades concretas de gerentes, directivos con altos logros en su gestión. Del análisis de días de trabajo de los "exitosos" se verificó que la conducta de ellos se caracterizaba así:

- pasan más del $75 \%$ de su tiempo conversando con otros;

- sus interlocutores son de una gama muy variada y llegan a él sin seguir una línea jerárquica;

- hablan de todo tipo de temas - planificación, organización, coordinación, control;

- hacen muchas preguntas;

- sus conversaciones tienen muchas bromas y referencias a asuntos extra trabajo;

- con frecuencia reaccionan a iniciativas de otros, modificando su agenda prevista; 
Este comportamiento podría calificarse de "atolondrado" desde la perspectiva del modelo tradicional de gestión. Este directivo cumple bien dos series de tareas cruciales: la toma de decisiones, la cual se nutre de información obtenida cara a cara, en un clima no burocrático, y la organización en red, a través de contactos personales con un grupo muy grande, la cualviabiliza la ejecución de las acciones.

\section{La planificación estratégica y la evaluación cualitativa}

En el marco de un estilo de gestión profesional, el directivo recurre a una planificación estratégica, no de carácter lineal e inflexible, que aspira a tener todo "bajo control" desde el comienzo. Diríamos que más que una forma de planificar es una forma de pensar la realidad y de abordarla. Se trata de retroalimentar la acción con datos relevantes de la realidad, recolectados mediante procesos rápidos, ágiles, que habilitan el proceso de toma de decisiones, lo orientan, lo rectifican, lo evalúan. Esta planificación conduce a la construcción de alternativas asociadas a los diversos escenarios que se van presentando. Lo que se trata es de acompañar el dinamismo de la realidad con una acción planificada que tenga la capacidad de ser flexible y de dar respuesta a la compleja y diversa realidad. Construir la viabilidad de la acción en medio de la adversidad es el desafío de un planificador de hoy. Este estilo de planificación es coexistente con los demás conceptos abordados (institución, actor, conflicto, negociación) que dan marco a la gestión.

Finalmente, la evaluación cualitativa del centro educativo es también una estrategia coadyuvante de la gestión deseada. Es importante la observación participante como fuente de datos en el marco de una evaluación cualitativa, que aspira a comprender la realidad en toda su complejidad. La evaluación que se plantea se interesa por la acción del centro en todas sus dimensiones, no sólo por los resultados académicos de los alumnos. La preocupación se centra en la entraña pedagógica del proceso educativo que se desarrolla en la institución, vista e interpretada por sus principales actores. Es preciso realizar una profundización que traspase la capa superficial del acontecer y de las simples calificaciones. Lo que importa es la dinámica que lleva consigo la estructura organizativa.

La escuela es una organización compleja en la que interactúan muchísimos elementos (materiales, personales, funcionales, etc) internamente y con diversos entornos. La escuela actúa como un sistema social abierto que se inserta en un medio amplio que la condiciona. Se considera al centro educativo como un ecosistema, como un conjunto de organismos de un ambiente determinado. El paradigma ecológico determina que sea más importante que normatizar la realidad (deber ser), comprenderla, explicarla, reconstruirla. El propósito fundamental de la evaluación así entendida es conocer cómo y por qué funciona la institución de una manera determinada, para comprenderla y mejorar su práctica.

\section{Bibliografía.}

AGUERRONDO, I. 1992 "La innovación educativa en América latina: balance de cuatro décadas". En Revista Perspectivas. Vol. XXII, nº 3: Bs. As.

ALMANDOZ, M. y ABATE, A. 1990 "Calidad de la Educación - Aportes para su análisis". En Serie Documentos para la regionalización y descentralización educativa: Bs.As.

ALVAREZ, M. y SANTOS M. 1996 Dirección de centros docentes Gestión por proyectos. Madrid: Escuela Española.

ESCUDERO, J. 1988 "La innovación y la organización escolar". En R. Pascual (Ed.) La gestión educativa ante la innovación y el cambio. Madrid: Narcea. 
ESCUDERO, J. 1995 "La innovación educativa en tiempos turbulentos". En Cuadernos de Pedagogía No 240: Madrid.

FILMUS, D. 1993 Para qué sirve la escuela. Bs. As: Tesis.

FRIGERIO, G. y otros 1992 Las instituciones educativas. Cara y Ceca. Bs.As.: Troquel.

FRIGERIO, G. y otros 1996 El análisis de la institución educativa. Hilos para tejer proyectos. Bs.As.: Santillana.

FRIGERIO, G. (Comp.) 1997 De Aquí y de Allá. Textos sobre la Institución Educativa y su Dirección. Bs.As.: Kapelusz.

GIMENO SACRISTÁN,J. Y PÉREZ GÓMEZ.M. 1995 Comprender y transformar la enseñanza. Madrid: Morata.

GIMENO SACRISTÁN, J (Coord.) 1995 La Dirección de los Centros: análisis de tareas. Madrid: M.E.C. - C.I.D.E.

LENTIJO, P. y otros 1995 Conducción escolar y transformación educativa. Bs.As.: Aique.

MATUS, C. 1987 Política, Planificación y Gobierno. Caracas: Fundación Altadir.

MUÑOZ-REPISO, M. 1995 "La calidad como meta" En Cuadernos de Pedagogía No 246: Madrid

O.C.D.E. 1990 Escuelas y calidad de la enseñanza. Informe Internacional. Barcelona: Paidós.

O.E.A. 1994 La Educación - Revista Interamericana de Desarrollo Educativo - Nos. 116 y 118 : Washington, U.S.A.

O.E.A. 1995 Revista Latinoamericana de innovaciones educativas $\mathrm{N}^{\circ} 21$ : Bs.As.

PAREDES, Z. 1997 EI Proyecto Institucional en el marco de las transformaciones educativas. Bs.As.: El Ateneo.

POGGI, M. (Comp.) 1998 Apuntes y Aportes para la Gestión Curricular. Bs.As.: Kapelusz.

POZNER, P. 1997 El directivo como gestor de aprendizajes escolares. Bs.As.: Aique.

SANTOS, M.A. 1993 Hacer visible lo cotidiano - Teoría práctica de la evaluación cualitativa de centros escolares. Madrid: Akal.

SENGE, P.1992 La quinta disciplina. Cómo impulsar el aprendizaje en la organización inteligente. Barcelona: Granica.

* Magister en Educación. Especialista en Innovación educativa. 